OPEN ACCESS

Edited by:

Karen Bieback,

Universität Heidelberg, Germany

Reviewed by:

Javier A. Enciso,

Universidad Científica del Sur, Peru

Philippe Bourin,

Independent Researcher, Toulouse,

France

*Correspondence:

Milena Botelho Pereira Soares

milena@bahia.fiocruz.br

tThese authors have contributed equally to this work and share first

authorship

Specialty section:

This article was submitted to

Stem Cell Research,

a section of the journal

Frontiers in Cell and Developmental

Biology

Received: 29 February 2020

Accepted: 16 April 2020

Published: 14 May 2020

Citation:

Daltro SRT, Meira CS, Santos IP,

Ribeiro dos Santos $R$ and

Soares MBP (2020) Mesenchymal

Stem Cells and Atopic Dermatitis:

A Review. Front. Cell Dev. Biol. 8:326.

doi: 10.3389/fcell.2020.00326

\section{Mesenchymal Stem Cells and Atopic Dermatitis: A Review}

\author{
Sérgio Ricardo Teixeira Daltro ${ }^{1+}$, Cássio Santana Meira' ${ }^{1 \dagger}$, Ivanilson Pimenta Santos ${ }^{1}$, \\ Ricardo Ribeiro dos Santos ${ }^{1,2,3}$ and Milena Botelho Pereira Soares ${ }^{1,2,3 *}$ \\ ${ }^{1}$ Gonçalo Moniz Institute, Oswaldo Cruz Foundation (FIOCRUZ), Salvador, Brazil, ${ }^{2}$ Health Institute of Technology, National \\ Industrial Learning Service - Integrated Manufacturing and Technology Campus (SENAI-CIMATEC), Salvador, Brazil, \\ ${ }^{3}$ National Institute of Science and Technology for Regenerative Medicine (INCT-REGENERA), Rio de Janeiro, Brazil
}

Mesenchymal stem/stromal cells (MSCs) are stromal-derived non-hematopoietic progenitor cells that reside in and can be expanded from various tissues sources of adult and neonatal origin, such as the bone marrow, umbilical cord, umbilical cord blood, adipose tissue, amniotic fluid, placenta, dental pulp and skin. The discovery of the immunosuppressing action of MSCs on T cells has opened new perspectives for their use as a therapeutic agent for immune-mediated disorders, including allergies. Atopic dermatitis (AD), a chronic and relapsing skin disorder that affects up to $20 \%$ of children and up to $3 \%$ of adults worldwide, is characterized by pruritic eczematous lesions, impaired cutaneous barrier function, Th2 type immune hyperactivation and, frequently, elevation of serum immunoglobulin E levels. Although, in the dermatology field, the application of MSCs as a therapeutic agent was initiated using the concept of cell replacement for skin defects and wound healing, accumulating evidence have shown that MSC-mediated immunomodulation can be applicable to the treatment of inflammatory/allergic skin disorders. Here we reviewed the pre-clinical and clinical studies and possible biological mechanisms of MSCs as a therapeutic tool for the treatment of atopic dermatitis.

Keywords: mesenchymal stem/stromal cells, atopic dermatitis, atopic eczema, immunomodulation, inflammatory skin diseases

\section{INTRODUCTION}

Atopic dermatitis (AD), commonly known as atopic eczema, is a typical dermal chronic inflammatory disorder characterized by eczematous cutaneous lesions and severe pruritus, representing a significant burden on health-care resources and patients' quality of life (Hoare et al., 2000; Boothe et al., 2017). The prevalence of AD is higher than $20 \%$ in children and $1-10 \%$ of adults in some countries and continues to increase, affecting not only low-income, but also developed countries (Nutten, 2015; Reed and Blaiss, 2018; Sacotte and Silverberg, 2018).

$\mathrm{AD}$ is considered the most expensive cutaneous disorder in the world, followed by acne and psoriasis (Sacotte and Silverberg, 2018). The treatment of AD is based on pharmacological intervention, through the use of corticosteroids, calcineurin inhibitors, leukotriene receptor antagonists and antihistamines (Nakagawa et al., 1994; Berth-Jones et al., 2003; Ring et al., 2012a,b). The use of these classes of drugs, however, not only provides temporary relief of symptoms, but also causes various adverse effects and drug resistance in long-term treatment (Saeki et al., 2016; 
Silverberg and Durán-McKinster, 2017). Therefore, the development of safe and effective therapies is necessary for the proper management of patients with AD.

Mesenchymal stem/stromal cells (MSCs), the most common stem cell used in cell therapy field, are multipotent, undifferentiated and self-renewing cells found in many adult and neonatal tissues (Pittenger et al., 1999; Dominici et al., 2006; Wei et al., 2013). MSCs have tissue repair potential through their self-renewal and differentiation abilities and is considered a strong modulator of the immune system through modulation of proliferation, recruitment and function of immune cells from innate and adaptive immune system (Herrero and Pérez-Simón, 2010; Hypnes et al., 2016; Zheng et al., 2018; Poggi and Zocchi, 2019). These features boosted pre-clinical and clinical investigations with the purpose of evaluate MSCs on autoimmune and immune-related diseases, such as asthma, systemic lupus erythematosus, rheumatoid arthritis, multiple sclerosis and skin diseases, such as AD (Sun et al., 2009; Nemeth et al., 2010; Wang et al., 2013; Na et al., 2014; Shin et al., 2017a; Li et al., 2020). In this review, we provide an overview of current reports regarding the use of MSCs as a therapeutic tool in atopic dermatitis, the challenges of conducting MSC studies in AD, as well as future directions needed to develop this field.

\section{ATOPIC DERMATITIS}

$\mathrm{AD}$ is characterized by severe itchiness, being one of the most common chronic inflammatory skin diseases, affecting up to onefifth of the population in developed countries (Weidinger and Novak, 2016). AD can occur in any age group or ethnicity, being the most common skin disease in children, especially infants under two years of age. In some countries, especially in Asia and Latin America, it affects around 20\% of children (Nagaraja et al., 1996; Odhiambo et al., 2009; Nutten, 2015; Page et al., 2016). Although most cases of childhood AD spontaneously resolve by adulthood, the disease persists in $10-30 \%$ of cases (Ellis et al., 2012). More rarely, the first symptoms develop in adulthood, being the prevalence of $\mathrm{AD}$ in adults of $1-3 \%$ (Eichenfield et al., 2014; Nutten, 2015).

The pathogenesis of $\mathrm{AD}$ is multifactorial, including genetic factors, epidermal barrier defects and immunopathogenic factors (Meagher et al., 2002). Regarding the immunopathogenic abnormalities, lymphocytes play a critical role, since $\mathrm{T}$ helper 2 (Th2) lymphocyte activation and the cytokines released by them lead to elevated production of immunoglobulin E ( IgE) (Figure 1), increased inflammation in the skin, and aggravate the skin barrier defect in AD (Meagher et al., 2002; Klonowska et al., 2018). The initial course of $A D$ is characterized by a biphasic inflammation, where a Th2 profile predominates, with increased levels of several cytokines, including interleukin-4 (IL4), IL-13, IL-17, IL-22, IL-31, and thymic stromal lymphopoietin (TSLP) (Olivry et al., 2016; Chaudhary et al., 2019). This immune signature exists in lesional and non-lesional skin, indicating a systemic switch to a Th2 profile. In chronic AD skin lesions, a Th1/Th0 dominance has been described with increased production of interferon-gamma (IFN- $\gamma$ ), IL-6, IL12 and granulocyte-macrophage colony-stimulating factor (GMCSF) (Figure 2). In addition to cytokines produced from Th1 and Th2 cells, IL-17, produced from Th17 cells, has been reported to contribute to pathogenesis of $\mathrm{AD}$. Interleukin-17 stimulates the production of IL- 6 and IL- 8 by human keratinocytes, which lead to increased T cell migration to the skin (Nutten, 2015; Miossec and Kolls, 2012; Sidburry and Khorsand, 2017; Campione et al., 2020). Interestingly, MSCs derived from skin samples from patients with chronic $\mathrm{AD}$ contributes to pathogenesis of disease through production of several Th1/Th17 cytokines and chemokines, such as CCL2, CCL20, CXCL2, CXCL5, IL-6, IL-8, IL-12, IL-17A, IL-21, transforming growth factor $\beta$ (TGF- $\beta$ ) and IFN- $\gamma$ (Orciani et al., 2017).

The clinical manifestations of AD vary with age. Infants (0-2 years) typically present erythematous papules and vesicles on the cheeks, forehead, neck and scalp, whereas children (2 years of age to puberty) exhibit dry skin and lichenified papules and plaques in flexural areas of the limbs. In adulthood, the predominant areas of eczema are the flexural folds, the face and neck, the upper arms and back, hands, feet, fingers and toes (McKenna and Doward, 2008; Weidinger and Novak, 2016; Kapur et al., 2018). Regardless of age, $\mathrm{AD}$ affects the patients' quality of life, once implies in sleep deprivation, financial costs and employment loss (Carroll et al., 2005; Lewis-Jones, 2006; Nutten, 2015).

Currently, there is no cure or prevention technique for $\mathrm{AD}$ and, therefore, treatment focuses on disease progression control and alleviation of symptoms (Carr, 2013). Due to the multifactorial pathogenetic mechanisms of $\mathrm{AD}$, a single therapeutic approach is hardly capable of achieving disease control. Topical treatment with moisturizers, emollients or corticosteroids, oral therapy with immunomodulators (corticosteroids, calcineurin inhibitors, leukotriene receptor antagonists and antihistamines) and antibiotics have been the basis for the management of atopic dermatitis (Ring et al., 2012a,b; Aoki et al., 2019). In general, topical treatment is the first option of choice, being effective for the most patients with mild disease. Systemic therapy may be offered to those with severe disease or treatment-resistant eczema, however, invariably, in the long term, comes along with side effects (Apfelbacher et al., 2013; Wong et al., 2017; Aoki et al., 2019). New therapeutic approaches, such as monoclonal antibodies, are passing through the drug discovery pipeline and may reinforce the therapeutic arsenal against $\mathrm{AD}$ in a near future (Weidinger and Novak, 2016; Snast et al., 2018; Pistone et al., 2019).

\section{MSCs CHARACTERISTICS AND IMMUNOMODULATORY PROPERTIES}

MSCs were first described in the 70's as a cell population with the ability of self-renewing and as precursor cells of osteogenic lineage (Friedenstein et al., 1970). Since then, MSCs have been the target of numerous investigations and, due to their therapeutic potential, it is the most studied stem cell type, with more than 1,000 clinical trials, at various phases, recorded in the clinical 


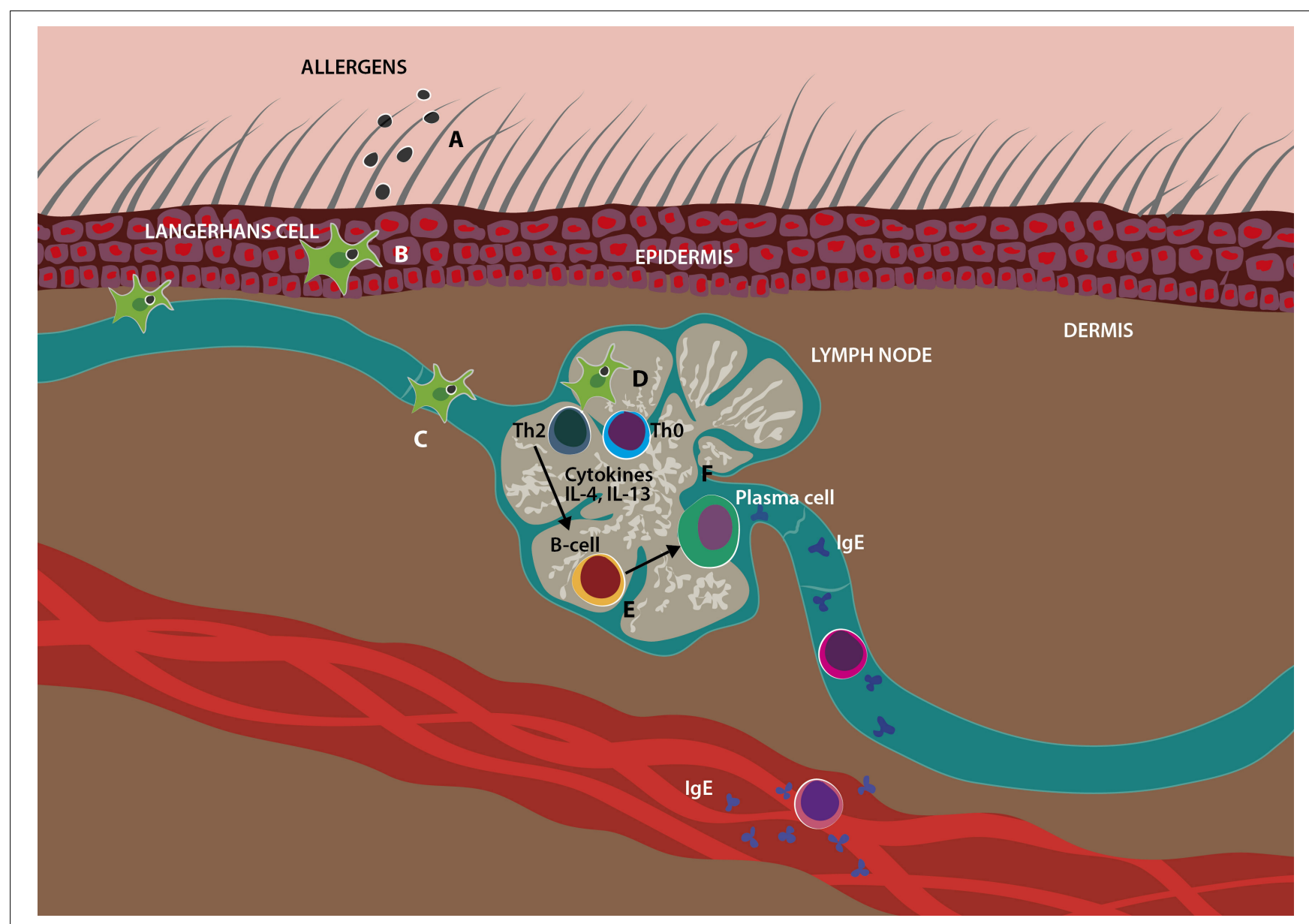

FIGURE 1 | Skin barrier dysfunction undergoing sensitization in AD. Allergens penetrating the skin (A) can be captured by Langerhans cells, which migrate to a regional draining lymph nodes $\mathbf{( B , C )}$. Langerhans cells present the allergen to a naïve $T$ cells, causing polarization to a Th-2 phenotype which secrete cytokines, such as IL-4 and IL-13 (D), that stimulate B cells to become plasma cells and secrete allergen-specific IgE (E,F).

trials database (clinicaltrials.gov as of January 2020). MSCs have a potential for differentiating into a variety of mesenchymal cell types, including adipocytes, chondrocytes, myoblasts and osteoblasts (Chamberlain et al., 2007; Glenn and Whartenby, 2014). MSCs are a heterogeneous population of cells that can be obtained by different sources, such as adipose tissue, amniotic fluid, bone marrow, dental pulp, skin, placenta, umbilical cord, and umbilical cord blood (Bianco et al., 2001; Lee et al., 2004; Lu et al., 2006; Guimarães et al., 2011; Antoniadou and David, 2016; Loukogeorgakis and De Coppi, 2017). Due to the pleiotropic nature of MSCs, the International Society for Cellular Therapy (ISCT) listed the minimum criteria and markers of MSCs in 2006 (Dominici et al., 2006). Briefly, MSCs should have plastic-adherence when maintained in standard culture conditions, capacity to in vitro differentiation into three cells types (adipocytes, chondrocytes and osteoblasts) and positive expression of specific cell surface markers, such as CD73, CD90 and CD105, while being negative to markers such as CD11b, CD14, CD19, CD34, CD45, CD79, and human leukocyte antigen - DR isotype (HLA-DR) (Dominici et al., 2006; Boxall and Jones, 2012).
MSCs emerged as an attractive cell type for the treatment of a variety of diseases, mainly injured tissues and immunemediated diseases, due to its ability in modulate innate and adaptive immune system (Wei et al., 2013; Glenn and Whartenby, 2014; Golchin et al., 2019). In the innate immune system, MSCs are able to promote macrophage polarization to M2 phenotype (Kim and Hematti, 2009), inhibit the release of antimicrobial products by neutrophils (Raffaghello et al., 2008), suppress degranulation and production of tumor necrosis factor alpha (TNF- $\alpha$ ) by mast cells (MC) (Brown et al., 2011), inhibit natural killer cells (NK) activation and production of pro-inflammatory cytokines (Sotiropoulou et al., 2006), and affect dendritic cell (DC) maturation, cytokine secretion and migration to lymph nodes (Chiesa et al., 2011). Regarding the adaptive immune system, MSCs inhibit B cell proliferation and affect antibodies production (Corcione et al., 2005), and, most importantly, affects $\mathrm{T}$ cell function, by inhibiting $\mathrm{T}$ cell proliferation through arresting at G0/G1 cell cycle phase, suppressing the development of Th1 and Th17 cells and favoring the development of antiinflammatory Th2 and Treg populations (Di Nicola et al., 2002; Aggarwal and Pittenger, 2005). 


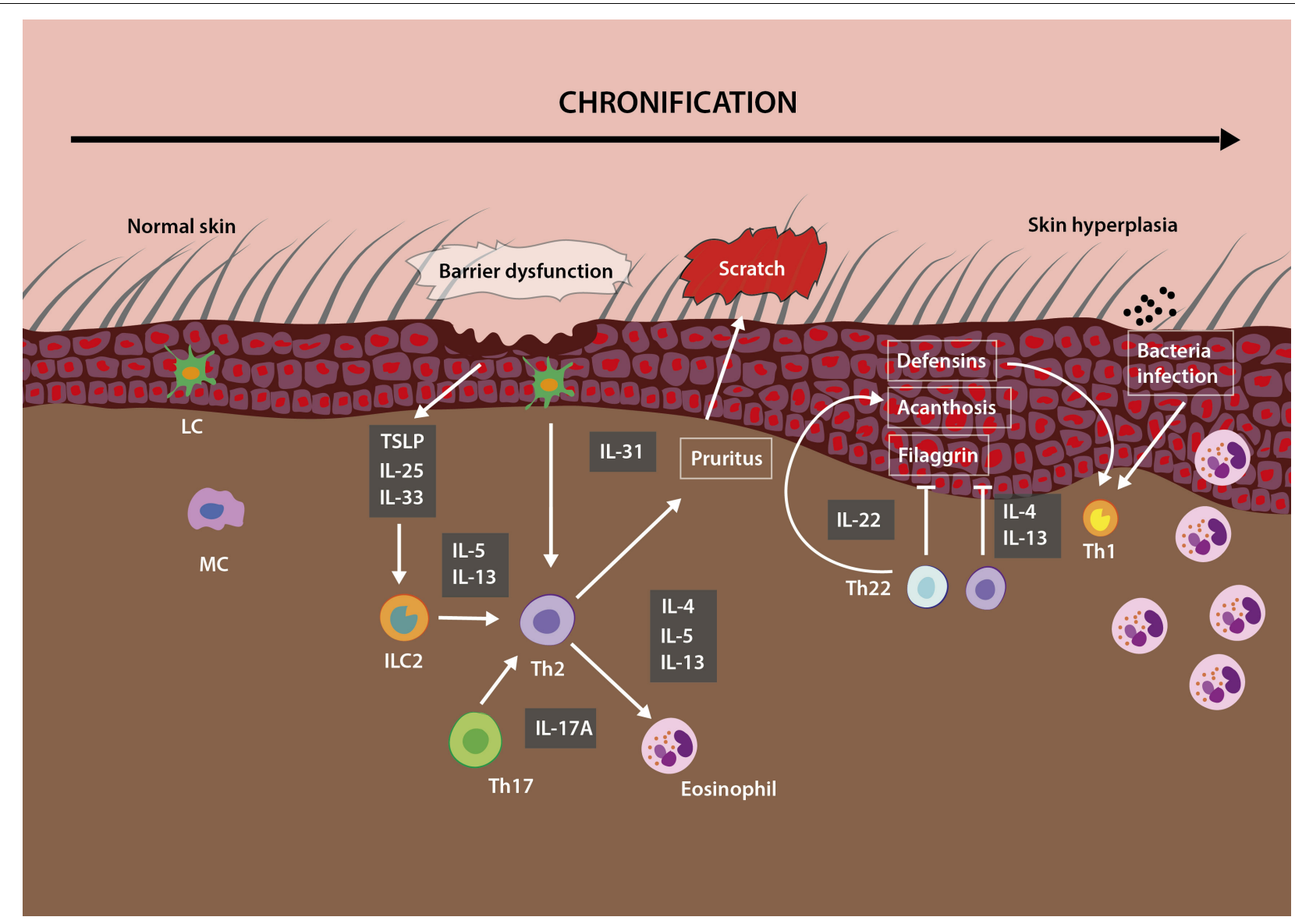

FIGURE 2 | Immune responses involved in chronification of lesions in AD. Scratching resulting from pruritus (the main symptom of AD), makes keratinocytes react by releasing cytokines important for inflammation, including TSLP (thymic stromal lymphopoetin), IL-33, and IL-25. IL-33 activates innate lymphoid cells 2 (ILC2) and Th2 lymphocytes. The release of IL-31 stimulates even more the pruritus. In response to IL-22, keratinocytes proliferate, resulting in diffuse epidermal hyperplasia. Eosinophils accumulate in chronic atopic skin. MC: mast cells; LC: Langerhans cells; ILC2: Innate lymphoid cell 2.

\section{MSCs AND ATOPIC DERMATITIS}

Over the last few years, the immunomodulatory effect of MSCsbased therapy has been described in animal models and in human beings, showing a significant improvement in the clinical presentation by inhibiting the activation of $\mathrm{T}$ and $\mathrm{B}$ cells and, consequently, the release of anti-inflammatory cytokines (IL-10 and TGF- $\beta$ ), by decreasing the proliferation of IL- 4 and IFN $\gamma$, and by decreasing the production of $\operatorname{lgE}$ (Dias et al., 2019).

Although several studies have demonstrated that the allergic progress in $\mathrm{AD}$ could be suppressed by MSCs derived from human umbilical cord blood (UCB-MSC), bone marrow (BMMSC) or adipose tissue (AD-MSC) by modulating multiple targets, there are some important issues to be considered in the stem cell-based therapy, such as the stem cell type used, number of cells transplanted, preconditioning of the cell preparation, relevant targets of the therapy, route and frequencyofadministration (Na et al., 2014; Kim et al., 2015; Shin et al., 2017b; Kim D. S. et al., 2018).

Human umbilical cord-derived mesenchymal stem cells (hUCB-MSCs) produced a significant protective and therapeutic effect against Dermatophagoides farinae $(D f)$-induced $\mathrm{AD}$ in mice by inhibiting MC degranulation. The protective effect was observed more prominently when local subcutaneous (SC) injection of MSCs was performed, when compared with intravenous (IV) administration, showing considerably importance in choosing the route of administration (Shin et al., 2017b). In another study, two different doses (low dose: $2 \times 10^{5}$; high dose: $2 \times 10^{6}$ ) of human adipose-derived mesenchymal stem cells (hAD-MSCs) were compared in a $D f$-induced mouse AD model (Shin et al., 2017a). The hAD-MSCs were injected intravenously in this study and interestingly, the higher dose of hAD-MSCs significantly reduced the clinical severity of AD in mice compared to the low dose group.

Another example of the complexity of stem cell-based therapy was demonstrated in a study in which hUCB-MSCs were pretreated with MC granules, enhancing their therapeutic effects, as observed by the attenuation of AD signs in a NC/Nga mouse model. Moreover, it was shown that hUCB-MSCs primed with mast cell granules suppressed the activation of MCs and B lymphocytes more efficiently than naïve MSCs, both in vitro and in vivo (Lee et al., 2019). 
However, the underlying mechanisms by which MSCs attenuate allergic responses is relatively unclear, considering that most studies have not focused on local, lesion specific therapeutic approaches, but rather on the regulation of systemic inflammatory responses (Kim et al., 2017). Accumulating data indicate that MSCs are not spontaneously immunosuppressive, but require stimulation for acquiring their immunomodulatory properties. In particular, the most important priming factors of MSCs are IFN- $\gamma$, TNF- $\alpha$, and IL- $1 \beta$. The release and binding of IFN- $\gamma$ on its receptor expressed by MSCs are key steps for the induction of their immunomodulatory properties, not only for various T cell subtypes, but also against B and NK cells (Kim M. et al., 2018; Najar et al., 2018; Wobma et al., 2018). During the synergistic action of IFN- $\gamma$ and TNF- $\alpha$, an increased production of IL-6, IL-8, HGF, PGE 2 and cyclooxygenase-2 (COX-2) was observed (Na et al., 2014; Lee and Song, 2018).

\section{EFFECTS OF MSCs ON T CELLS IN THE CONTEXT OF AD}

The pathogenesis of $\mathrm{AD}$ is mainly associated with $\mathrm{T}$ cell abnormalities, especially CD4 ${ }^{+} \mathrm{T}$ cells (Leung, 1999; Meagher et al., 2002). Based on the profile of cytokines produced, can be classified in Th1 or Th2 cells, and both cells play a critical role in AD pathogenesis (Hanifin and Chan, 1999; Leung, 1999). In the acute phase, Th2 response predominates with increased levels of several cytokines, including IL-4 and IL-13, which induce the production of IgE by B cells (Chaudhary et al., 2019). During the chronic phase, a predominance of Th1 profile has been described, with increased production of IL-5, IL-12, and IFN$\gamma$, the latter being responsible for inhibiting Th2 lymphocytes (Leung, 1999). Therefore, due to the central role of Th1/Th2 balance in the pathogenesis of $\mathrm{AD}$, any therapy able to modulate these profiles may potentially interfere with the evolution of the disease (Boothe et al., 2017).

Interestingly, MSCs present strong immunomodulatory effects on lymphocyte function (Di Nicola et al., 2002; Aggarwal and Pittenger, 2005; Batorov et al., 2015; Li et al., 2016), including immunomodulatory effects shown in AD models (Table 1). In $\mathrm{BALB} / \mathrm{c}$ mice with $\mathrm{AD}$ induced by ovalbumin (OVA), treatment with superoxide dismutase 3-transduced MSCs (SOD3-MSCs) suppressed the recruitment of $\mathrm{T}$ cells into the skin and reduced the number of $\mathrm{CD}^{+}$and $\mathrm{CD}^{+} \mathrm{T}$ cells in the spleen and lymph node (Sah et al., 2018). A similar inhibitory effect on $\mathrm{T}$ cell recruitment to the skin was observed in $\mathrm{BALB} / \mathrm{c}$ mice with $\mathrm{AD}$ induced by Aspergillus fumigatus (Af) and treated with hUCB-MSCs primed with poly I:C or IFN- $\gamma$ and in NC/Nga mice with $\mathrm{AD}$ induced by $D f$ and treated with hUCB-MSCs pretreated with MC granules (Lee et al., 2019; Park et al., 2019).

In vivo findings of $\mathrm{T}$ cell inhibition in $\mathrm{AD}$ are supported by in vitro experiments in which co-cultures of MSCs with $\mathrm{T}$ lymphocytes showed suppression of $\mathrm{T}$-cell proliferation and cytokine (IFN $\gamma$ and IL-4) production (Na et al., 2014). Moreover, inhibition of T-bet and GATA-3 expression, which are transcription factors regulating IFN $\gamma$ and IL-4 production, respectively, was also observed after treatment with BM-MSCs.
Using L-NMMA, a nitric oxide (NO) inhibitor, the suppressive effect of BM-MSCS on T-cell proliferation and IFN $\gamma$ production, but not IL-4 production, was reversed (Na et al., 2014).

\section{EFFECTS OF MSCs ON B-CELLS AND IgE PRODUCTION IN THE CONTEXT OF AD}

B cells play a critical role in the immune system and abnormalities on these cells functions result in a variety of chronic inflammation and autoimmune-mediated disorders, including AD (Simon et al., 2008; Nagel et al., 2009). MSCs are well known as suppressors of B cell function (Corcione et al., 2005; Asari et al., 2009; De Miguel et al., 2012) and, therefore, several studies evaluated their effect on B cells in AD models (Table 1).

Initially, $\mathrm{Na}$ et al. (2014) evaluated the effects of BM-MSC in $\mathrm{BALB} / \mathrm{c}$ mice with $\mathrm{AD}$ induced by OVA. An intravenous injection of BM-MSCs was shown to suppress $\mathrm{AD}$ via inhibition of IgE production by B cells ( $\mathrm{Na}$ et al., 2014). A reduction in IgE production in sera was also found in NC/Nga mice with $\mathrm{AD}$ induced by $D f$ and treated with hAD-MSCs or hUCB-MSCs (Shin et al., 2017b; Lee et al., 2019).

In vitro experiments have confirmed the inhibitory effects of different types of MSCs on IgE production by B cells stimulated with lipopolysaccharide (LPS) or anti-CD40, as well as the inhibition of $\mathrm{B}$ cell proliferation and maturation ( $\mathrm{Na}$ et al., 2014; Shin et al., 2017a; Lee et al., 2019). Interestingly, the effects of MSCs on B cell were attenuated with the addition of celecoxib, a selective COX-2 inhibitor (Shin et al., 2017b; Lee et al., 2019). In addition, BM-MSCs-induced IgE suppression is associated downregulation of activation-induced cytidine deaminase (AID) and B lymphocyte-induced maturation protein-1 (BLIMP-1), important regulators for class switch DNA recombination (CSR) and B-cell differentiation (Na et al., 2014). In short, we can see that MSCs modulate the maturation, proliferation and production of IgE, through CSR or COX-2$\mathrm{PGE}_{2}$ pathway.

\section{EFFECTS OF MSCs ON MAST CELLS IN THE CONTEXT OF AD}

Mast cells regulate trafficking and functions of cells involved in the skin inflammatory response through the release of several soluble mediators, including chemokines, cytokines and growth factors (Liu et al., 2011). In AD, mast cells contribute to the pathogenesis of both acute and chronic lesions, and its presence is supported by higher concentrations of its products such as IL-4, IL-13 and histamine in AD patients (Ring and Thomas, 1989; Hamid et al., 1996; Liu et al., 2011). In addition, mast cell degranulation has been shown to correlate with $\mathrm{AD}$ severity (Zhao et al., 2006).

Remarkably, MSCs are able to inhibit mast cell degranulation in AD mouse models (Table 1; Kim et al., 2015; Kim M. et al., 2018; Sah et al., 2018; Lee et al., 2019; Park et al., 2019). In NC/Nga mice with $\mathrm{AD}$ induced by $D f$, hUCB-MSCs injected 
TABLE 1 | Effect of MSCs on experimental animal models of atopic dermatitis.

\begin{tabular}{|c|c|c|c|c|c|c|}
\hline \multirow[t]{2}{*}{ Model } & \multirow[t]{2}{*}{ Animals (strain) } & \multicolumn{5}{|c|}{ MSCs } \\
\hline & & Source & Route & Effect & Mechanism and note & References \\
\hline- & Dogs & cAD-MSCs & IV & $\mathrm{N}$ & $\begin{array}{l}\text { Systemic administration of cADMSCs appears } \\
\text { safe but ineffective }\end{array}$ & Hall et al., 2010 \\
\hline AD (OVA-induced) & $\begin{array}{l}\text { Mouse (BALB/c or } \\
\mathrm{C} 3 \mathrm{H} / \mathrm{HeN})\end{array}$ & BM-MSCs & IV & Y & $\begin{array}{l}\text { T-cell supression via NO; B cell supression via } \\
\text { CSR }\end{array}$ & Na et al., 2014 \\
\hline $\mathrm{AD}(D f$-induced $)$ & Mouse (Nc/Nga) & hUCB-MSCs & SC & Y & $\begin{array}{l}\text { Inhibition of MC degranulation throught PG2 } \\
\text { and TGF } \beta 1\end{array}$ & Kim et al., 2015 \\
\hline$A D(D f$-induced $)$ & Mouse (Nc/Nga) & hAD-MSCs & IV & Y & B cell supresion via (COX)-2 & Shin et al., 2017b \\
\hline $\begin{array}{l}\text { AD } \\
\text { (DNCB-induced) }\end{array}$ & Mouse (BALB/C) & hAD-MSCs & IV & Y & $\begin{array}{l}\text { Regulating the expression of MIP-2, } \\
\text { miR-122a-SOCS1, and Th1/Th2 responses }\end{array}$ & Kim M. et al., 2018 \\
\hline AD (OVA-induced) & Mouse (BALB/c) & hSOD3-MSCs & SC & Y & $\begin{array}{l}\text { Suppression of response elicited by } \\
\text { keratinocytes, mast cells, neutrophils, DCs, and } \\
\text { T cells through multiple mechanisms }\end{array}$ & Sah et al., 2018 \\
\hline- & Dogs & cAD-MSCs & IV & Y & Supression of canine PBMC proliferation & Villatoro et al., 2018 \\
\hline AD (Df-induced) & Mouse (Nc/Nga) & hUCB-MSCs & SC & Y & $\begin{array}{l}\text { Preconditionng of MSC with MC granules } \\
\text { optimizes the supression of MC and B cells }\end{array}$ & Lee et al., 2019 \\
\hline $\mathrm{AD}(A f$-induced $)$ & Mouse (BALB/C) & hUCB-MSCs & SC & Y & $\begin{array}{l}\text { Control both eosinophil-associated Th2 } \\
\text { immunity and neutrophil-related Th17 }\end{array}$ & Park et al., 2019 \\
\hline
\end{tabular}

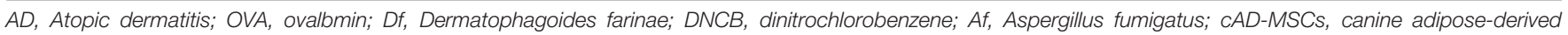

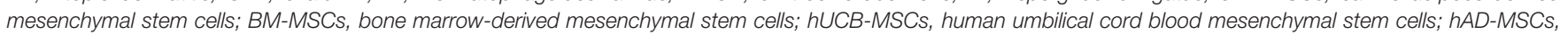

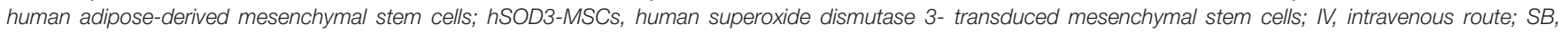

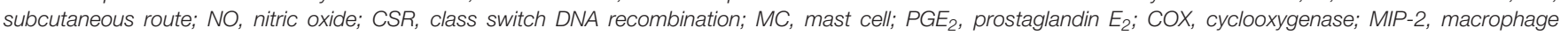

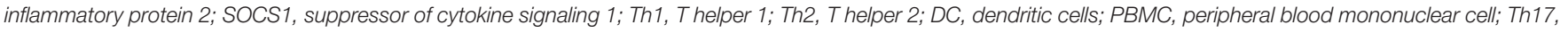
Thelper 17.

TABLE 2 | Clinical trials of MSCs in AD.

\begin{tabular}{|c|c|c|c|c|c|}
\hline Type & Participants & Stem cells source & $\begin{array}{l}\text { Route of } \\
\text { administration }\end{array}$ & Result & References \\
\hline Phase I; Phase lla & 7 adults; 27 adults & hUCB-MSCs & Subcutaneous & $\begin{array}{l}\downarrow \text { lgE levels } \downarrow \text { Neutrophil number } 6 / 11 \\
(55 \%) \text { : EASI50 in high dose treated group }\end{array}$ & Kim et al., 2016 \\
\hline Phase I & 13 adults & MSCs & Intravenous & Ongoing & NCT02888704 \\
\hline Phase II & 118 adults & hAD-MSCs & Intravenous & Recruiting & NCT04137562 \\
\hline Phase I; Phase II & 20 adults; 72 adults & hBM-MSCs & Intravenous & Not yet recruiting & NCT04179760 \\
\hline
\end{tabular}

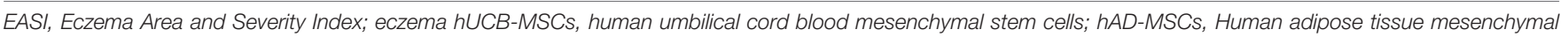
stem cells; hBM-MSCs, human bone marrow mesenchymal stem cells. NCT; Identification code given to each clinical study registered on ClinicalTrials. gov.

subcutaneously decreased the number of total degranulated mast cells, as well as the rate of degranulation (Kim et al., 2015; Lee et al., 2019). The inhibitory effect of MSCs on mast cell degranulation was also confirmed in $\mathrm{BALB} / \mathrm{c}$ mice with $\mathrm{AD}$ induced by dinitrochlorobenzene (DNCB) and treated with hADMSCs and in BALB/c mice with AD induced by OVA and treated with SOD3-MSCs (Kim D. S. et al., 2018; Sah et al., 2018).

The inhibitory effect of MSC on mast cell degranulation was initially attributed to COX-2-PGE 2 pathway (Kim et al., 2010). Previous reports revealed that human $\mathrm{MC}$ express multiple $\mathrm{PGE}_{2}$ receptors (EP receptors) that activate $\left(\mathrm{EP}_{3}\right)$ or inhibit $\left(\mathrm{EP}_{2}\right)$ mast cell degranulation (Feng et al., 2006; Kay et al., 2006; Wang and $\mathrm{Lau}, 2006)$. The addition of antagonists for the $\mathrm{EP}_{2}$ and $\mathrm{EP}_{4}$, but not for the $\mathrm{EP}_{1}$ and $\mathrm{EP}_{3}$, reduced the effect of hUCB-MSCs on mast cell degranulation (Kim et al., 2010). In agreement with this finding, MSCs treated with celecoxib, a selective COX-2 inhibitor, have a weak inhibitory effect on mast cell degranulation (Shin et al., 2017a; Lee et al., 2019). Taken together, the data support the involvement of COX-2-PGE 2 pathway on MSC immunosuppression effect of mast cell degranulation.

In addition, Kim et al. (2015), using sirRNA, observed a loss in degranulation-inhibiting effect of MSCs with down-regulation of TGF- $\beta 1$, which can be explained by the inhibitory effect of TGF$\beta 1$ produced on mast cells expression of high-affinity IgE receptor (Fc\&RI), a critical component for IgE-mediated degranulation (Gomez et al., 2005).

Another mechanism related to MSCs effects on mast cell degranulation is the reduction of reactive oxygen species (ROS) production, since ROS triggers mast cell activation through both FceRI and histamine $\mathrm{H}_{4}$ receptor (H4R)-dependent pathways (Son et al., 2006; Swindle et al., 2008; Sah et al., 2018). Moreover,

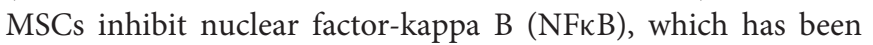
reported to bind to the $\mathrm{H} 4 \mathrm{R}$ promoter region and, thereby, drive H4R upregulation and activation (Cogé et al., 2001).

Due to the promising profile of different types of MSCs to treat $\mathrm{AD}$, several strategies to improve the inhibitory effects of MSCs in 
mast cell degranulation and on other immune cells are in process of development. These include the use of MSCs treated with muramyl dipeptide (stimulus for NOD activation) (Kim et al., 2015), MSCs genetically modified to overexpress superoxide dismutase 3 (Sah et al., 2018), hUCB-MSC primed with poly I:C or IFN- $\gamma$ (Park et al., 2019) and MSCs preconditioning with mast cell granules (Lee et al., 2019). All these strategies were shown to improve the inhibitory effects of MSCs on mast cell degranulation, as well as in other immune cells, such as B and $\mathrm{T}$ cells. In addition, extracts from hUCB-MSC and exosomes derived from hAD-MSC also ameliorated $\mathrm{AD}$, reinforcing the importance of the paracrine effects of MSCs in AD context (Cho et al., 2018; Song et al., 2019).

\section{CLINICAL TRIALS OF MSCs THERAPY IN AD}

Despite the evidence indicating the benefits of MSCs in the treatment of $\mathrm{AD}$ in pre-clinical studies, to the date of this review, only one clinical trial (phase I/IIa) was published with subjects with AD (Table 2). A single cell administration hUCB-MSCs subcutaneously was performed in 34 adult participants with moderate-to-severe AD. Using the eczema area and severity index (EASI) score, an improvement in $\mathrm{AD}$ symptoms was observed in the groups treated with the two doses $\left(2.5 \times 10^{7}\right.$ cells, low dose; $5 \times 10^{7}$ cells, high dose) tested. In particular, the group treated with the higher dose of hUCB-MSCs showed a 50\% reduction in EASI score in 6 of 11 (55\%) subjects, without the appearance of side effects. In addition, the serum IgE levels and the number of eosinophils, typical biomarkers of $\mathrm{AD}$, also decreased after treatment (Kim et al., 2017). Despite the encouraging results, this study has limitations, such as the small number of participants, its open label design and the lack of a placebo group. New studies

\section{REFERENCES}

Aggarwal, S., and Pittenger, M. E. (2005). Human mesenchymal stem cells modulate allogeneic immune cell responses. Blood 105, 1815-1822. doi: 10. 1182/blood-2004-04-1559

Antoniadou, E., and David, A. L. (2016). Placental stem cells. Best Pract. Res. Clin. Obstet. Gynaecol. 31, 13-29. doi: 10.1016/j.bpobgyn.2015.08.014

Aoki, V., Lorezini, D., Orfali, R. L., Zaniboni, M. C., Oliveira, Z. N. P., RivittiMachado, M. C., et al. (2019). Consensus on the therapeutic management of atopic dermatitis- Brazilian Society of Dermatology. An. Bras. Dermatol. 94, 67-75. doi: 10.1590/abd1806-4841.2019940210

Apfelbacher, C. J., Van Zuuren, E. J., Fedorowicz, Z., Jupiter, A., Matterne, U., and Weisshaar, E. (2013). Oral H1 antihistamines as monotherapy for eczema. Cochrane Database Syst. Rev. 28:CD007770. doi: 10.1002/14651858.CD007770. pub2

Asari, S., Itakura, S., Ferreri, K., Liu, C. P., Kuroda, Y., Kandeel, F., et al. (2009). Mesenchymal stem cells suppress B-cell terminal differentiation. Exp. Hematol. 37, 604-615. doi: 10.1016/j.exphem.2009.01.005

Batorov, E. V., Shevela, E. Y., Tikhonova, M. A., Batorova, D. S., Ushakova, G. Y., Sizikova, S. A., et al. (2015). Mesenchymal stromal cells improve early lymphocyte recovery and $\mathrm{T}$ cell reconstitution after autologous hematopoietic stem cells transplatation in patients with malignant lymphomas. Cell. Immunol. 297, 80-86. doi: 10.1016/j.cellimm.2015.07.001 with an experimental design including placebo groups and a larger number of patients, which are ongoing or to be started (Table 2), may bring new data to help define the clinical future of MSCs therapy in AD (National Library of Medicine, 2020).

\section{CONCLUSION}

Atopic dermatitis has become a significant public health problem due to its increasing prevalence, and there is a need for new therapeutic options for this disease. Evidence of therapeutic efficacy and mechanisms of action produced in pre-clinical studies indicate that MSC-based cell therapy is a promising approach for the treatment of AD. There is a need, however, for the conduction of double-blinded, placebo-controlled studies, to indicate the potential clinical application of MSCs, especially taking into account the complex pathogenesis of AD. Additional studies aiming at uncovering the mechanisms of action of MSC in atopic dermatitis may help define better therapeutic strategies for this disease.

\section{AUTHOR CONTRIBUTIONS}

SD and CM designed the study and wrote the manuscript. SD and IS conceived the artwork and performed the bibliographical research. RR and MS supervised the writing. All the authors revised and approved the final version of the manuscript.

\section{FUNDING}

The authors of this work acknowledge for the financial support provided by the Brazilian Research Council (CNPq)/MS Grant No. 443909/2018-0.

Berth-Jones, J., Damstra, R. J., Golsch, S., Livden, J. K., Van Hooteghem, O., Allegra, F., et al. (2003). Twice weekly fluticasone propionate added to emolient maintenance treatment to reduce risk of relapse in atopic dermatitis: randomised, double blind, parallel group study. BMJ 326:1367. doi: 10.1136/ bmj.326.7403.1367

Bianco, P., Rimiucci, M., Gronthos, S., and Robery, P. G. (2001). Bone marrow stromal stem cells: nature, biology, and potential applications. Stem Cells 19, 180-192. doi: 10.1634/stemcells.19-3-180

Boothe, D. W., Tarbox, J. A., and Tarbox, M. B. (2017). Atopic dermatitis: pathophysiology. Adv. Exp. Med. Biol. 1027, 21-37. doi: 10.1007/978-3-31964804-0_3

Boxall, S. A., and Jones, E. (2012). Markers for characterization of bone marrow multipotential stromal cells. Stem Cells Int. 2012:975871. doi: 10.1155/2012/ 975871

Brown, J. M., Nemeth, K., Kushnir-Sukhov, N. M., Metcalfe, D. D., and Mezey, E. (2011). Bone marrow stromal cells inhibit mast cell function via a COX2dependent mechanism. Clin. Exp. Allergy 41, 526-534. doi: 10.1111/j.13652222.2010.03685.x

Campione, E., Lanna, C., Diluvio, L., Cannizzaro, M. V., Grelli, S., Galluzzo, M., et al. (2020). Skin immunity and its dysregulation in atopic dermatitis, hidradenitis supurativa and vitiligo. Cell Cycle 19, 257-267. doi: 10.1080/15384101.2019.17 07455 
Carr, W. W. (2013). Topical calcineurin inhibitors for atopic dermatitis: review and treatment recomendations. Paediatr. Drugs 15, 303-310. doi: 10.1007/s40272013-0013-9

Carroll, C. L., Balkrishnan, R., Feldman, S. R., Fleischer, A. B., and Manuel, J. C. (2005). The burden of atopic dermatitis: impact on the patient, family, and society. Pediatr. Dermatol. 22, 192-199. doi: 10.1111/j.1525-1470.2005.22303.x

Chamberlain, G., Fox, J., Ashton, B., and Middleton, J. (2007). Concise review: mesenchymal stem cells: their phenotype, differentiation capacity, immunological features, and potential for homing. Stem Cells 25, 2739-2749. doi: 10.1634/stemcells.2007-0197

Chaudhary, S. K., Singh, S. K., Kumari, P., Kanwal, S., Soman, S. P., Choudhury, S., et al. (2019). Alterations in circulating concentrations of IL-17, IL-31 and total IgE in dogs with atopic dermatitits. Vet. Dermatol. 30:383-e114. doi: 10.1111/ vde. 12762

Chiesa, S., Morbelli, S., Morando, S., Massollo, M., Marini, C., and Bertoni, A. (2011). Mesenchymal stem cells impair in vivo T-cell priming by dendritic cells. Proc. Natl. Acad. Sci. U.S.A. 108, 17384-17389. doi: 10.1073/pnas.1103650108

Cho, B. S., Kim, J. O., Ha, D. H., and Yi, Y. W. (2018). Exosomes derived from human adipose tissue-derived mesenchymal stem cells alleviate atopic dermatitis. Stem Cells Res. Ther. 9:187. doi: 10.1186/s13287-018-0939-5

Cogé, F., Guénin, S. P., Rique, H., Boutin, J. A., and Galizzi, J. P. (2001). Structure and expression of the human histamine H4-receptor gene. Biochem. Biophys. Res. Commun. 284, 301-309. doi: 10.1006/bbrc.2001.4976

Corcione, A., Benvenuto, F., Ferretti, E., Giunti, D., Cappiello, V., Cazzanti, F., et al. (2005). Human mesenchymal stem cells modulate B-cell functions. Blood 107, 367-372. doi: 10.1182/blood-2005-07-2657

De Miguel, M. P., Fuentes-Julián, S., Blázquez-Martínez, A., Pascual, C. Y., Aller, M. A., Arias, J., et al. (2012). Immunosuppressive properties of mesenchymal stem cells: advances and applications. Curr. Mol. Med. 12, 574-591. doi: 10. 2174/156652412800619950

Di Nicola, M., Carlo-Stella, C., Magni, M., Milanesi, M., Longoni, P. D., Matteucci, P., et al. (2002). Human bone marrow stromal cells suppress T-lymphocyte proliferation induced by cellular or nonspecific mitogenic stimuli. Blood 99, 3838-3843. doi: 10.1182/blood.v99.10.3838

Dias, I. E., Pinto, P. O., Barros, L. C., Viegas, C. A., Dias, I. R., and Carvalho, P. P. (2019). Mesenchymal stem cells therapy in companion animals: useful for immune-mediated diseases? BMC Vet. Res. 15:358. doi: 10.1186/s12917-0192087-2

Dominici, M., Le Blanc, K., Mueller, I., Slaper-Cortenbach, I., Marini, F., and Krause, D. (2006). Minimal criteria for defining multipotent mesenchymal stromal cells. The international society for cellular therapy position statement. Cytotherapy 8, 315-317. doi: 10.1080/14653240600855905

Eichenfield, L. F., Tom, W. L., Chamlin, S. L., Feldman, S. R., Hanifin, J. M., Simpson, E. L., et al. (2014). Guidelines of care for the management of atopic dermatitis: section 1. diagnosis and assessment of atopic dermatitis. J. Am. Acad. Dermatol. 70, 338-351. doi: 10.1016/j.jaad.2013.10.010

Ellis, C. N., Mancini, A. J., Paller, A. S., Simpson, E. L., and Eichenfield, L. F. (2012). Understanding and managing atopic dermatitis in adult patients. Semin. Cutan. Med. Surg. 31(3 Suppl.), S18-S22. doi: 10.1016/j.sder.2012.07.006

Feng, C., Beller, E. M., Bagga, S., and Boyce, J. A. (2006). Human mast cells express multiple EP receptors for prostaglandina E2 that differentially modulate activation responses. Blood 107, 3243-3250. doi: 10.1182/blood-2005-07-2772

Friedenstein, A. J., Chailakhjan, R. K., and Lalykina, K. S. (1970). The development of fibroblast colonies in monolayer cultures of guinea-pig bone marrow and spleen cells. Cell Tissue Kinet. 3, 393-403. doi: 10.1111/j.1365-2184.1970. tb00347.x

Glenn, J. D., and Whartenby, K. A. (2014). Mesenchymal stem cells: emerging mechanisms of immunomodulation and therapy. World J. Stem Cells 26, 526-539. doi: 10.4252/wjsc.v6.i5.526

Golchin, A., Farahany, T. Z., Khojasteh, A., Soleimanifar, F., and Ardeshirylajimi, A. (2019). The clinical trials of mesenchymal stem cell therapy in skin diseases: an update and concise review. Curr. Stem Cell Res. Ther. 14, 22-33. doi: 10.2174/ 1574888X13666180913123424

Gomez, G., Ramirez, C. D., Rivera, J., Patel, M., Norozian, F., Wright, H. V., et al. (2005). TGF-beta 1 inhibits mast cell Fc epsilon RI expression. J. Immunol. 174, 5987-5993. doi: 10.4049/jimmunol.174.10.5987

Guimarães, E. T., Cruz, G. S., Jesus, A. A., Lacerda de Carvalho, A. F., Rogatto, S. R., Pereira, L. V., et al. (2011). Mesenchymal and embryonic characteristics of stem cells obtained from mouse dental pulp. Arch. Oral Biol. 56, 1247-1255. doi: 10.1016/j.archoralbio.2011.05.008

Hall, M. N., Rosenkrantz, W. S., Hong, J. H., Griffin, C. E., and Mendelsonhn, C. M. (2010). Evaluation of the potential use of adipose-derived mesenchymal stromal cells in the treatment of canine atopic dermatitis: a pilot study. Vet. Ther. 11, E1-E14.

Hamid, Q., Naseer, T., Minshall, E. M., Song, Y. L., Boguniewicz, M., and Leung, D. Y. (1996). In vivo expression of IL-12 and IL-13 in atopic dermatitis. J. Allergy Clin. Immunol. 98, 225-231. doi: 10.1016/s0091-6749(96)70246-4

Hanifin, J. M., and Chan, S. (1999). Bichemical and imunologic mechanisms in atopic dermatitis: new targets for emerging therapies. J. Am. Acad. Dermatol. 41, 72-77. doi: 10.1016/s0190-9622(99)70410-x

Herrero, C., and Pérez-Simón, J. A. (2010). Immunomodulatory effect of mesenchymal stem cells. Braz. J. Med. Biol. Res. 43, 425-430. doi: 10.1590/ S0100-879X2010007500033

Hoare, C., Li Wan, P. A., and Williams, H. (2000). Systematic review of treatments for atopic eczema. Health Technol. Assess. 4, 1-191. doi: 10.1111/bjd.14588

Hypnes, K., Bright, R., Proudman, S., Haynes, D., Gronthos, S., and Bartold, M. (2016). Immunomodulatory properties of mesenchymal stem cell in experimental arthritis in rat and mouse models: a systematic review. Semin. Arthritis Rheum. 46, 1-19. doi: 10.1016/j.semarthrit.2016.02.008

Kapur, S., Watson, W., and Carr, S. (2018). Atopic dermatitis. Allergy Asthma Clin. Immunol. 14(Suppl. 2):52. doi: 10.1186/s13223-018-0281-6

Kay, L. J., Yeo, W. W., and Peachell, P. T. (2006). Prostaglandin E2 activates EP2 receptors to inhibit human lung mast cell degranulation. Br. J. Pharmacol. 147, 707-713. doi: 10.1038/sj.bjp.0706664

Kim, D. S., Jang, I. K., Lee, M. W., Ko, Y. J., Lee, D. H., Lee, J. W., et al. (2018). Enhanced immunosuppressive properties of human mesenchymal stem cells primed by interferon- $\gamma$. EBioMedicine 28, 261-273. doi: 10.1016/j.ebiom.2018. 01.002

Kim, M., Lee, S. H., Kim, Y., Know, Y., Park, Y., Lee, H. K., et al. (2018). Human adipose tissue-derived mesenchymal stem cells attenuate atopic dermatitis by regulating the expression of MIP-2, miR-122a-SOCS1 axis, and Th1/Th2 responses. Front. Pharmacol. 9:1175. doi: 10.3389/fphar.2018.01175

Kim, H. S., Lee, J. H., Roh, K. H., Jun, H. J., Kang, K. S., and Kim, T. Y. (2017). Clinical trial of human umbilical cord blood-derived stem cells for the treatment of moderate-to-severe atopic dermatitis: phase I/IIa studies. Stem Cells 35, 248-255. doi: 10.1002/stem.2401

Kim, H. S., Yun, J. W., Shin, T. H., Lee, S. H., Lee, B. C., Yu, K. R., et al. (2015). Human umbilical cord blood mesenchymal tem cell-derived PGE2 and TGF$\beta 1$ alleviate atopic dermatits by reducing mast cell degranulation. Stem Cells 33 , 1254-1266. doi: 10.1002/stem.1913

Kim, J., and Hematti, P. (2009). Mesenchymal stem cell-educated macrophages: a novel type of alternatively activated macrophages. Exp. Hematol. 37, 1445-1453. doi: 10.1016/j.exphem.2009.09.004

Kim, Y., Eom, S., Kim, K., Lee, Y. S., Choe, J., Hahn, J. H., et al. (2010). Transglutaminase II interacts with rac1, regulates production of reactive oxygen species, expression of snail, secretion of Th2 cytokines and mediates in vitro and in vivo allergic inflammation. Mol. Immunol. 47, 1010-1022. doi: 10.1016/ j.molimm.2009.11.017

Klonowska, J., Glen, J., Nowicki, R. J., and Trzeciak, M. (2018). New cytokines in the pathogenesis of atopic dermatitis New therapeutic targets. Int. J. Mol. Sci. 19:3086. doi: 10.3390/ijms19103086

Lee, B. C., Kim, J. J., Lee, J. Y., Kang, I., Shin, N., Lee, S. E., et al. (2019). Diseasespecific primed human adult stem cells effectively ameliorate experimental atopic dermatitis in mice. Theranostics 9, 3608-3621. doi: 10.7150/thno. 32945

Lee, D. K., and Song, S. U. (2018). Immunomodulatory mechanisms of mesenchymal stem cells and their therapeutical applications. Cell. Immunol. 326, 68-78. doi: 10.1016/j.cellimm.2017.08.009

Lee, O. K., Kuo, T. K., Chen, W. M., Lee, K. D., Hsieh, S. L., and Chen, T. H. (2004). Isolation of multipotent mesenchymal stem cells from umbilical cord blood. Blood 103, 1669-1675. doi: 10.1182/blood-2003-05-1670

Leung, Y. M. (1999). Pathogenesis of atopic dermatitis. J. Allergy Clin. Immunol. 104, S99-S108. doi: 10.1016/s0091-6749(99)70051-5

Lewis-Jones, S. (2006). Quality of life and childhood atopic dermatitis: the misery of living with childhood eczema. Int. J. Clin. Pract. 60, 984-992. doi: 10.1111/j. 1742-1241.2006.01047.x 
Li, H., Tian, Y., Xie, L., Liu, X., Huang, Z., and Su, W. (2020). Mesenchymal stem cells in allergic diseases: current status. Allergol. Int. 69, 35-45. doi: 10.1016/j. alit.2019.08.001

Li, X., Xu, Z., Bai, J., Yang, S., Zhao, S., Zhang, Y., et al. (2016). Umbilical cord tissue-derived mesenchymal stem cells induce lymphocyte apoptosis and cell cycle arrest by expression of indoleamine 2,3-dioxygenase. Stem Cells Int. 2016:7495135. doi: 10.1155/2016/7495135

Liu, F. T., Goodarzi, H., and Chen, H. Y. (2011). IgE, mast cells, and eosinophils in atopic dermatitis. Clin. Rev. Allergy. Immunol. 41, 298-310. doi: 10.1007/ s12016-011-8252-4

Loukogeorgakis, S. P., and De Coppi, P. (2017). Concise review: amniotic fluid stem cells: the know, the unknow, and potential regenerative medicine applications. Stem Cells 35, 1663-1673. doi: 10.1002/stem.2553

Lu, L. L., Liu, Y. J., Yang, S. G., Zhao, Q. J., Wang, X., Gong, X., et al. (2006). Isolation and characterization of human umbilical cord mesenchymal stem cells with hematopoesis-supportive function and other potentials. Haematologica 91, 1017-1026.

McKenna, S. P., and Doward, L. C. (2008). Quality of life of children with atopic dermatitis and their families. Curr. Opin. Allergy Clin. Immunol. 8, 228-231. doi: 10.1097/ACI.0b013e3282ffd6cc

Meagher, L. J., Wines, N. Y., and Cooper, A. J. (2002). Atopic dermatitis: review of immunopathogenesis, and advances in immunosuppressive therapy. Australas. J. Dermatol. 43, 247-254. doi: 10.1046/j.1440-0960.2002.00610.x

Miossec, P., and Kolls, J. K. (2012). Targeting IL-17 and TH17 cells in chronic Inflammation. Nat. Rev. Drug Discov. 11, 763-776. doi: 10.1038/nrd 3794

Na, K., Yoo, H. S., Zhang, Y. X., Choi, M. S., Lee, K., Yi, T. G., et al. (2014). Bone marrow-derived clonal mesenchymal stem cells inhibit ovalbumin-induced atopic dermatitis. Cell Death Dis. 5:e1345. doi: 10.1038/cddis.2014.299

Nagaraja, R., Kanwar, A. J., Dhar, S., and Singh, S. (1996). Frequency and significance of minor clinical features in various age-related subgroups of atopic dermatits in children. Pediatr. Dermatol. 13, 10-13. doi: 10.1111/j.1525-1470. 1996.tb01178.x

Nagel, A., Hertl, M., and Eming, R. (2009). B-cell-directed therapy for inflammatory skin diseases. J. Invest. Dermatol. 129, 289-301. doi: 10.1038/jid. 2008.192

Najar, M., Krayem, M., Merimi, M., Burny, A., Meuleman, N., Bron, D., et al. (2018). Insights into inflammatory priming of mesenchymal stromal cells: functional biological impacts. Inflamm. Res. 67, 467-477. doi: 10.1007/s00011018-1131-1

Nakagawa, H., Etoh, T., Ishibashi, Y., Higaki, Y., Kawashima, M., Torii, H., et al. (1994). Tacrolimus ointment for atopic dermatitis. Lancet 344:883.

National Library of Medicine (2020). ClinicalTrials.gov. Available online at: https: //clinicaltrials.gov/ct2/home (accessed January 20, 2020).

Nemeth, K., Keane-Myers, A., Brown, J. M., Metcalfe, D. D., Gorham, J. D., Bundoc, V. G., et al. (2010). Bone marrow stromal cells use TGF- $\beta$ to suppress allergic responses in a mouse model of ragweed-induced asthma. Proc. Natl. Acad. Sci. U.S.A. 107, 56652-56657. doi: 10.1073/pnas.0910720107

Nutten, S. (2015). Atopic demartitis: global epidemiology and risk factors. Ann. Nutr. Metab. 66(Suppl.), 8-18. doi: 10.1159/000370220

Odhiambo, J. A., Williams, H. C., Clayton, T. O., Robertson, C. F., and Asher, M. I. (2009). Global variations in prevalence of eczema symptoms in children from ISAAC phase three. J. Allergy Clin. Immunol. 124, 1251-1258. doi: 10.1016/j. jaci.2009.10.009

Olivry, T., Mayhew, D., Paps, J. S., Linder, K. E., Peredo, C., Rajpal, D., et al. (2016). Early activation of Th2/Th22 inflammatory and pruritogenic pathways in acute canine AD skin lesions. J. Invest. Dermatol. 136, 1961-1969. doi: 10.1016/j.jid. 2016.05.117

Orciani, M., Campanati, A., Caffarini, M., Ganzetti, G., Consales, V., Lucarini, G., et al. (2017). T helper (Th)1, Th17 and Th2 imbalance in mesenchymal stem cells of adult patients with atopic dermatitis: at the origin of the problem. Br. J. Dermatol. 176, 1569-1576. doi: 10.1111/bjd.15078

Page, S. S., Weston, S., and Loh, R. (2016). Atopic dermatitis in children. Aust. Fam. Phys. 45, 293-296.

Park, A., Park, H., Yoon, J., Kang, D., Kang, M. H., Park, Y. Y., et al. (2019). Priming with toll-like receptor 3 agonist or interferon-gamma enhances the therapeutic effects of human mesenchymal stem cells in a murine model of atopic dermatitis. Stem Cell Res. Ther. 10:66. doi: 10.1186/s13287-019-1164-6
Pistone, G., Tilotta, G., Gurreri, R., Castelli, E., Curiale, S., and Bongiorno, M. R. (2019). Real-life practice: rapid improvement in itch symptomatology in patients with atopic dermatitis treated with dupilumab. J. Dermatolog. Treat. doi: 10.1080/09546634.2019.1628914 [Epub ahead of print].

Pittenger, M. F., Mackay, A. M., Beck, S. C., Jaiswal, R. K., Douglas, R., Mosca, J. D., et al. (1999). Multilineage potential of adult human mesenchymal stem cells. Science 284, 143-147. doi: 10.1126/science.284.5411.143

Poggi, A., and Zocchi, M. R. (2019). Immunomodulatory properties of mesenchymal stromal cells: still unresolved "Yin and Yang". Curr. Stem. Cell Res. Ther. 14, 344-350. doi: 10.2174/1574888X14666181205115452

Raffaghello, L., Bianchi, G., Bertolotto, M., Montecucco, F., Busca, A., Dallegri, F., et al. (2008). Human mesenchymal stem cells inhibit neutrophil apoptosis: a model for neutrophil preservation in the bone marrow niche. Stem Cells 26, 151-162. doi: 10.1634/stemcells.2007-0416

Reed, B., and Blaiss, M. S. (2018). The burden of atopic dermatitis. Allergy Asthma Proc. 39, 406-410. doi: 10.2500/aap.2018.39.4175

Ring, J., Alomar, A., Bieber, T., Deleuran, M., Fink-Wagner, A., Gelmetti, C., et al. (2012a). Guidelines for treatment of atopic eczema (atopic dermatitis) part I. J. Eur. Acad. Dermatol. Venereol. 26, 1045-1060. doi: 10.1111/j.1468-3083.2012. 04635.x

Ring, J., Alomar, A., Bieber, T., Deleuran, M., Fink-Wagner, A., Gelmetti, C., et al. (2012b). Guidelines for treatment of atopic eczema (atopic dermatitis) part II. J. Eur. Acad. Dermatol. Venereol. 26, 1076-1093. doi: 10.1111/j.1468-3083.2012. 04636.x

Ring, J., and Thomas, P. (1989). Histamine and atopic eczema. Acta Derm. Venereol. Suppl. 144, 70-77.

Sacotte, R., and Silverberg, J. I. (2018). Epidemiology of adult atopic dermatits. Clin. Dermatol. 36, 595-605. doi: 10.1016/j.clindermatol.2018.05.007

Saeki, H., Nakahara, T., Tanaka, A., Kabashima, K., Sugaya, M., Murota, H., et al. (2016). Clinical practice guidelines for the management of atopic dermatitis 2016. J. Dermatol. 43, 1117-1145. doi: 10.1111/1346-8138.13392

Sah, S. K., Agrahari, G., Nguyen, C. T., Kim, Y. S., Kang, K. S., and Kim, T. Y. (2018). Enhanced therapeutic effects of human mesenchymal stem cells transduced with superoxide dismutase 3 in a murine topic dermatitis-like skin inflammation model allergy. Allergy 73, 2364-2376. doi: 10.1111/all.13594

Shin, T. H., Kim, H. S., Choi, S. W., and Kang, K. S. (2017a). Mesenchymal stem cell therapy for inflammatory skin diseases: clinical potential and mode of action. Int. J. Mol. Sci. 18, 1-25. doi: 10.3390/ijms18020244

Shin, T. H., Lee, B. C., Choi, S. W., Shin, J. H., Kang, I., Lee, Y. L., et al. (2017b). Human adipose tissue-derived mesenchymal stem cells alleviate atopic dermatits via regulation of B lymphocyte maturation. Oncotarget 8, 512-522. doi: 10.18632/oncotarget.13473

Sidburry, R., and Khorsand, K. (2017). Evolving concepts in atopic dermatitis. Curr. Allergy Asthma Rep. 17:42. doi: 10.1007/s11882-017-0710-5

Silverberg, N. B., and Durán-McKinster, C. (2017). Special considerations for therapy of pediatric atopic dermatitis. Dermatol. Clin. 35, 351-363. doi: 10. 1016/j.det.2017.02.008

Simon, D., Hosli, S., Kostylina, G., Yawalkar, N., and Simon, H. U. (2008). AntiCd20 (rituximab) treatment improves atopic eczema. J. Allergy Clin. Immunol. 121, 122-128. doi: 10.1016/j.jaci.2007.11.016

Snast, I. S., Reiter, O., Hodak, E., Friedland, R., Mimouni, D., and Leshem, Y. A. (2018). Are biological efficacious in atopic dermatits? A systematic review and meta-anaylsis. Am. J. Clin. Dermatol. 19, 145-165. doi: 10.1007/s40257-0170324-7

Son, A., Nakamura, H., Kondo, N., Matsuo, Y., Liu, W., Oka, S., et al. (2006). Redox regulation of mast cell histamine release in thioredoxin-1 (TRX) transgenic mice. Cell Res. 16, 230-239. doi: 10.1038/sj.cr.7310031

Song, J. Y., Kang, H. J., Ju, H. M., Park, A., Park, H., Hong, J. S., et al. (2019). Umbilical cord-derived mesenchymal stem cell extracts ameliorate atopic dermatitis in mice by reducing the $\mathrm{T}$ cell responses. Sci. Rep. 9:6623. doi: 10.1038/s41598-019-42964-7

Sotiropoulou, P. A., Perez, S. A., Gritzapis, A. D., Baxevanis, C. N., and Papamichail, M. (2006). Interactions between human mesenchymal stem cells and natural killer cells. Stem Cells 24, 74-85. doi: 10.1634/stemcells.2004-0359

Sun, L., Akiyama, K., Zhang, H., Yamaza, T., Hou, Y., Zhao, S., et al. (2009). Mesenchymal stem cell transplantation reverses multiorgan dysfunction in systemic lupus erythematosus mice and humans. Stem Cells 27, 1421-1432. doi: $10.1002 /$ stem. 68 
Swindle, E. J., DeLeo, F. R., and Metcalfe, D. D. (2008). Intracellular superoxide production by mast cells. J. Allergy Clin. Immunol. 121(Suppl. 1):S111. doi: 10.1016/j.jaci.2007.12.441

Villatoro, A. J., Hermida-Prieto, M., Fernández, V., Fariñas, F., Alcoholado, C., and Rodríguez-García, M. I. (2018). Allogeneic adipose-derived mesenchymal stem cell therapy in dogs with refractory atopic dermatitis: clinical efficacy and safety. Vet. Rec. 183:654. doi: 10.1136/vr.104867

Wang, L., Wang, L., Cong, X., Liu, G., Zhou, J., Bai, B., et al. (2013). Human umbilical cord mesenchymal stem cell therapy for patients with active rheumatoid arthritis: safety, and efficacy. Stem Cells Dev. 22, 3192-3202. doi: $10.1089 /$ scd. 2013.0023

Wang, X. L., and Lau, H. Y. A. (2006). Prostaglandin E2 potentiates the immunologically stimulated histamine release from human peripheral bloodderived mast cells through EP1/EP3 receptors. Allergy 61, 503-506. doi: 10 . 1111/j.1398-9995.2006.01043.x

Wei, X., Yang, X., Han, Z. P., Qu, F. F., Shao, L., and Shi, Y. F. (2013). Mesenchymal stem cells: a new trend for cell therapy. Acta Pharmacol. Sin. 34, 747-754. doi: 10.1038/aps.2013.50

Weidinger, S., and Novak, N. (2016). Atopic dermatitis. Lancet 387, 1109-1122. doi: 10.1016/S0140-6736(15)00149-X

Wobma, H. M., Kanai, M., Ma, S. P., Shih, Y., Li, H. W., Duran-Struuck, R., et al. (2018). Dual IFN- $\gamma /$ hypoxia priming enhances immunosuppression of mesenchymal stromal cells through regulatory proteins and metabolic mechanisms. J. Immunol. Regen. Med. 1, 45-56. doi: 10.1016/j.regen.2018. 01.001
Wong, I. T. Y., Tsuyuki, R. T., Cresswell-Melville, A., and Drucker, A. M. (2017). Guidelines for the management of atopic dermatitis (eczema) for pharmacists. Can. Pharm. J. 150, 285-297. doi: 10.1177/17151635177 10958

Zhao, L., Jin, H., She, R., Hu, Y., Xiao, C., Yu, Y., et al. (2006). A rodent model for allergic dermatitis induced by flea antigens. Vet. Immunol. Immunopathol. 114, 285-296. doi: 10.1016/j.vetimm.2006. 08.016

Zheng, G., Huang, R., Qiu, G., Ge, M., Wang, J., Shu, Q., et al. (2018). Mesenchymal stromal cell-derived extracellular vesicles: regenerative and immunomodulatory effects and potential aplicattions in sepsis. Cell Tissue Res. 374, 1-15. doi: 10.1007/s00441-0182871-5 doi: 10.1007/s00441-018-2871-5

Conflict of Interest: The authors declare that the research was conducted in the absence of any commercial or financial relationships that could be construed as a potential conflict of interest.

Copyright (c) 2020 Daltro, Meira, Santos, Ribeiro dos Santos and Soares. This is an open-access article distributed under the terms of the Creative Commons Attribution License (CC BY). The use, distribution or reproduction in other forums is permitted, provided the original author(s) and the copyright owner(s) are credited and that the original publication in this journal is cited, in accordance with accepted academic practice. No use, distribution or reproduction is permitted which does not comply with these terms. 